\title{
La culpa de escribir
}

\author{
The Blame of Writing
}

Culpa de escrever

\section{Graciela Montaldo}

\section{columbia university}

Profesora del Departamento de Español y Portugués de Columbia University, Nueva York. Doctora en Letras de la Universidad de Buenos Aires. Ha escrito artículos y ensayos para libros y revistas internacionales, $\mathrm{y}$ ha editado varios volúmenes colectivos, entre ellos, The Argentina Reader (con Gabriela Nouzeilles, Duke University Press, 2002). Entre sus libros se encuentran: De pronto, el campo. Literatura argentina y tradición rural (Beatriz Viterbo Editora, 1993), La sensibilidad amenazada. Fin de siglo y modernismo (Beatriz Viterbo Editora, 1994), Ficciones culturales y fábulas de identidad en América Latina (Beatriz Viterbo Editora, 1999), A propriedade da cultura (Chapecó, 2004), Zonas ciegas (Fondo de Cultura Económica, 2010). Correo electrónico: gm2168@columbia.edu

\footnotetext{
Artículo de reflexión

Publicado originalmente en la revista digital Coroto 3 (2012): 42-52.

Documento accesible en línea desde la siguiente dirección: http://revistas.javeriana.edu.co doi:10.11144/Javeriana.CL18-35.Icde
} 


\section{Resumen}

El artículo estudia las

relaciones entre la estética y

las instituciones culturales

en un caso de la narrativa

latinoamericana. A partir

de La novela luminosa, de Mario Levrero, se exploran los vínculos de la literatura con la experiencia, la autoridad, las instituciones y su peso en la producción estética contemporánea.

Palabras clave: Mario Levrero, instituciones culturales, autor, vanguardia.

Palabras descriptor: Levrero, Jorge Mario Varlotta, 1940-

2004 - Crítica e interpretación, organizaciones culturales, vanguardismo (Literatura).

\section{Abstract}

The article examines the relationship between aesthetics and cultural institutions in a case of Latin American narrative. From La novela luminosa by Mario Levrero, literature links with experience, authority, institutions and their weight in the contemporary aesthetic production are explored.

Keywords: Mario Levrero, cultural institutions, author, avant-garde.

Keywords plus: Levrero, Jorge Mario Varlotta, 1940-2004 Interpretation and criticism, cultural organizations, literatureexperimental.

\section{Resumo}

$\mathrm{O}$ artigo analisa as relações entre estética e instituições culturais num caso da narrativa latino-americana. A partir de $\mathrm{La}$ novela luminosa ( $\mathrm{O}$ romance luminoso), de Mario Levrero, exploram-se os vínculos da literatura côa experiência, a autoridade, as instituições e o seu peso na produção estética contemporânea.

Palavras-chave: Mario Levrero, instituições culturais, autor, vanguarda.

Palavras-chave descritores:

Levrero, Jorge Mario Varlotta, 1940-2004 - Criticism and interpretation, organizações culturais, avant garde (Literatura).

RECIBIDO: 6 DE ABRIL DE 2013. EVALUADO: 24 DE ABRIL DE 2013. ACEPTADO: 24 DE ABRIL DE 2013.

Cómo citar este artículo:

Montaldo, Graciela. "La culpa de escribir". Cuadernos de Literatura 18.35 (2014): 173-187. 


\section{Las series}

En 1930 la industria del cine en la Argentina sufre su primera gran crisis. No es difícil ligar esa crisis a la situación política: después del golpe militar de setiembre de ese año, muchas cosas cambian en la Argentina y la industria cinematográfica deberá no solo someterse a la censura, sino también a los oscuros negocios que imponen los sectores conservadores que privilegian a las distribuidoras extranjeras y estigmatizan la producción local. En ese año se filma una película institucional (pocas de ficción pueden hacerse entonces); se trata de la llamada Correos y telégrafos, de carácter promocional, que muestra el trabajo dentro del Correo Central y el recorrido completo de las cartas dentro del edificio del correo, desde que llegan hasta que salen, como una verdadera fábrica con línea de montaje. El filme fue propaganda institucional en su momento y hoy es una curiosidad que permite ver parte de la historia del cine nacional, así como también del diverso y complejísimo universo de la comunicación humana -desde la más íntima hasta la más formal-, sometido a la igualación del proceso de selección, a la maquinización y, especialmente, a la serialización por la que tiene que pasar, necesariamente, en la modernidad, el intento de alcanzar a otro a través de la escritura.

Cualquiera de nosotros puede aportar más imágenes de este tipo, que el cine hizo convencionales, cotidianas, naturales: las telefonistas alineadas frente a cientos de cables que conectan las llamadas, la veloz impresión de varias tiradas de periódicos. Desde fines del siglo XIX, la comunicación comienza a ser mediada por la técnica en el proceso de serialización. En el caso del teléfono y las cartas, muchas de esas comunicaciones pueden ser íntimas, mensajes en varias ocasiones secretos, que confían a la tecnología algo que tiene un solo y preciso destinatario. Lo privado -lo más privado, aquello que solo se puede decir sin estar presente- necesita pasar por, o servirse de, lo público para hacerse oír. O quizás lo privado, lo íntimo y lo secreto comienzan a existir cuando pueden expresarse a través de las mediaciones, que tratan de ocultar, precisamente, la forma en que la intimidad solo es posible cuando la delimitan la publicidad y el espectáculo. Por esta razón, frente a los intentos de darle forma a un conjunto de escrituras contemporáneas en la Argentina, conocidas como las escrituras del yo, quisiera centrarme no en las escrituras mismas sino en algunas formas que hacen que lo privado emerja. En este sentido, hoy todos los protocolos de comunicación tienden a hacer cada vez más visible lo íntimo o lo secreto; tienden a sacarlo a luz de manera reiterada. O, mejor, todo lo que se cuenta parece más comunicable cuando se hace en primera persona, incluso lo que se quiere decir de otro; incluso aquello que no pertenece a nadie; incluso aquello que se 
imagina ${ }^{1}$. Por eso, podría decir que si hay algo nuevo en la producción estética más reciente se trata de un pacto entre autores y lectores según el cual lo que se escribe o lee en primera persona -que puede ser leído autobiográficamente o no- recibe, bajo la forma de la primera persona, una atención especial, de algún modo se hace verosímil una situación, como si nuestro presente se hubiese instalado en la primera persona con cierta comodidad de enunciación, y registrara en esa lengua ya bastante convencional de la intimidad o la confesionalidad una multiplicidad de formas de interpelación. Pero la lengua en que nos comunicamos en nuestra época es una convención, y es por ello que quisiera referirme también al lugar donde las convenciones principian y se ponen en circulación: las instituciones.

Borges -maestro en el uso de la primera persona- propició la imagen de barajar todos los signos del alfabeto para escribir, con todas las combinaciones posibles, todos los textos posibles; Ricardo Piglia jugó con la idea de leer los escritos de Descartes no como filosofía sino como autobiografía, y aplicar ese método de lectura transgenérica a toda escritura; César Aira imaginó que toda la literatura había sido pasada a imágenes. También se podría pensar -y existe ya la máquina para hacerlo- en pasar todo lo escrito a una primera persona, en enunciar todo lo que se ha dicho como si lo dijera "yo". En todos estos ejercicios veo reclamos de época, es decir, la forma en que hoy estamos expuestos a la primera persona; esta, como forma privilegiada del intercambio comunicacional, genera protocolos específicos de enunciación, a los que resulta difícil escapar. Si esto es así, conviene situar el problema entonces más allá de la literatura y más allá de la Argentina, y pensar las formas en que los relatos circulan. Desde esta perspectiva quisiera explorar no los contenidos del yo ni la producción de intimidad, sino los aspectos ligados a la institucionalización de la primera persona, las formas en que se vuelve el lugar-común- de una forma del decir contemporáneo.

En un universo que es cada día más "cultural", que cada día se articula más en términos de relatos y donde la "producción de opinión" se vuelve un imperativo fomentado por las nuevas tecnologías, los sujetos culturales han ganado presiones para que se declaren el tópico de su propio discurso. Si varios críticos ven en esto un aspecto liberador de las presiones modernas por mantener un estatus autónomo ${ }^{2}$, una visión del arte como instancia política y

1 Escribí una versión primera de este trabajo para leer en el II Encuentro Internacional "Escrituras del yo" (Rosario, 18-20 de agosto de 2010), al que fui generosamente invitada por Alberto Giordano, a quien agradezco haberme puesto ante este desafío.

2 Es el caso de Josefina Ludmer, en Aquí América Latina. Ludmer define las escrituras latinoamericanas contemporáneas como literaturas posautónomas, colocadas en un más allá de las 
emancipadora", una crítica a lo que podríamos llamar lo "estéticamente correcto" " yo puntualizaría que las presiones y dispositivos para escribir en primera persona se han transformado, precisamente, en ese lugar de producción de la cultura al que ahora se le exige un yo que se haga cargo del discurso. Quisiera recurrir al argumento de un estudio sociológico reciente, que al analizar la escena de la subjetividad contemporánea, afirma que: "El individuo moderno 'libre' se ve compelido a coproducirse mediante un tipo de relaciones consigo mismo tan poderosas que lo hacen vender su fuerza de trabajo con el fin de vivir una vida que pueda mejorarse de forma sostenida" (Lorey 63). Lorey también sostiene que en los años sesenta el trabajo y las formas de vida alternativos se veían como una salida a la sujeción liberal, como una posibilidad de tener dominio sobre sí. Esas mismas condiciones ahora se han convertido en las más útiles desde el punto de vista económico, pues favorecen la flexibilidad que exige el mercado de trabajo, y el sujeto ha caído presa de aquella libertad que creyó conseguir. Algunos creen que han elegido las nuevas condiciones libremente, pero son ellas las que se les han impuesto a los ciudadanos contemporáneos. La liberación del yo, ganada a las presiones del disciplinamiento moderno, podría recibir -por "efecto boomerang" - todo aquello que formaba parte de su emancipación bajo la forma de una condena: sobrellevar la obligación de ser siempre una primera persona emancipada. Dentro de esta perspectiva, me interesa muy especialmente el diagnóstico de que hoy hay una falta de división entre ocio y trabajo, porque creo que allí se inserta también la proliferación de ese enunciado del sí mismo, cuando ya no se buscan las marcas de formas mediadas de intervención. Si el yo emerge como una tensión frente al mundo administrado, ¿qué pasa cuando esa tensión ya no hace frente sino que responde a una nueva forma de disciplinamiento? Por eso me detendré en un caso que revela algún punto de "resistencia" a esta tendencia, una práctica menos funcional al universo del yo. Voy a despegarme bastante de planteos más claramente textuales o literarios, como los de Giordano y Ludmer, para interrogar el afuera de la primera persona en el arte y su relación con la trama institucional en la que se despliega. No me internaré en la producción de la "literatura del yo" como género o como escritura específica, sino que trataré

divisiones realidad/ficción, buena o mala literatura.

3 Reinaldo Laddaga, en Estéticas de la emergencia. La formación de otra cultura de las artes, describe y analiza prácticas culturales que apelan a la creación de redes y comunidades que atienden a una participación política, estética y cultural.

4 Así lo ve Alberto Giordano en El giro autobiográfico de la literatura argentina actual. En este libro, el uso de la primera persona se identifica -al contrario de la interpretación de Ludmercon la redefinición de valores literarios. 
de ver, a partir de un ejemplo y su genealogía, algunos de los problemas a los que nos enfrenta escribir bajo la forma de la primera persona.

\section{Instituciones y desacuerdos}

Quisiera enfocar esta lectura en el problema que enfrentan la estética y la política dentro de las prácticas culturales contemporáneas. Voy a considerar un caso que habla de sí, pero en el cual hablar de sí es un problema y no una celebración, y es un problema no solo para el sujeto que escribe sino para la institución literaria y su relación con el mercado. En las últimas dos décadas la literatura se ha convertido en un fenómeno cultural que puede arrojar beneficios en buena parte del mundo en una escala mucho menor que las artes plásticas, pero de todos modos considerable. Premios literarios, ferias del libro internacionales multitudinarias, becas y subsidios de fundaciones internacionales, revistas culturales y blogs ayudaron a promover nuevamente la literatura como una práctica que puede ser absorbida por el mercado y ha sido socialmente aplaudida por salir de cierto solipsismo para hacerse, finalmente, un bien de consumo extendido ${ }^{5}$. Como en el campo del arte, la complejidad del mercado global afecta la producción literaria de diversas maneras. Genera un uso y una resistencia frente al mercado, un posicionamiento ante las formas en que las instituciones internacionales -globales- sugieren o simplemente imponen tendencias, y también las formas en que las producciones culturales de países periféricos admiten y resisten esas relaciones (y sus consumos). No estoy pensando en un mundo dividido en centro y periferias, sino en un proceso globalizador que define prácticas culturales con obras cada vez más uniformes, en el que los procedimientos forman parte de un proceso de serialización y cada obra debe mostrar su singularidad recurriendo a la primera persona. Por eso, la producción de la intimidad, de la subjetividad, de lo privado, de lo secreto, no es ajena a esta serialización que, como procedimiento, es recurrente en la escritura y en las artes en general, y mucho más en las más invasivas prácticas comunicacionales: la televisión, los diarios y las revistas.

En Le partage du sensible: estétique et polique (2000), Jacques Rancière analiza la estética y la política como formas no correlativas de representación. No hay diálogo ni alianzas entre ellas, dice, sino una real confrontación. Estética y política, bajo la modernidad, tienen los mismos problemas pero ambas los enfrentan de diversos modos a través de diferentes prácticas. En gran parte de la producción latinoamericana contemporánea -y en su historia- estética y política son

5 Me refiero a la literatura en general -a todo lo que circula bajo ese nombre-, a la más involucrada con el mercado como a la más sofisticada estéticamente. 
dos órdenes que siguen siendo problemáticos. Para buena parte de los escritores y escritoras, lo que sucede en uno de esos órdenes no puede sino afectar al otro. Las decisiones que se toman en un ámbito tienen sus consecuencias, necesariamente, en el otro; pero no se trata de una relación especular, de identidad, sino de una suerte del efecto que produce un campo sobre el otro, por lo cual no habría identificación de contenidos sino algún tipo de conmoción que reacomoda los contenidos generales. Y esto sucede tanto en las producciones individuales como en el sistema cultural en conjunto. La política genera conflictividad; la estética abre modos de ver, saca los problemas de la tradición y los confronta con el sentido común. Para Rancière, la política es siempre un desacuerdo: un momento de conflicto. Desacuerdo, para Rancière, es una forma especial de situación de habla, en la cual uno de los interlocutores entiende y a la vez no entiende lo que dice el otro; desacuerdo es el conflicto entre el que dice blanco y el que entiende blanco pero tiene otra idea de lo que es la blancura", diferente a la de su interlocutor. Por esta razón, la política es la práctica en la que las palabras no coinciden con las cosas. Exactamente como en la literatura...

Desde esta perspectiva podemos revisar algunas estrategias de negociación entre mercado, estética y política cuando una primera persona se pronuncia, cuando el yo emerge como apropiación de un discurso de la subjetividad que nos interpela tratando de abolir la conflictividad de su enunciación. Dentro de la escena uniforme del presente, algunos escritores y artistas establecen formas para continuar desarrollando su arte, pero no de la manera en que el mercado y las instituciones dirigen su producción. Usan la estética como un instrumento de desacuerdo dentro de las obras mismas, y en sus manos la estética ataca las instituciones a la vez que sostiene el lugar hoy central de estas en la producción estética. La estética está allí concebida no como la raíz del arte sino como un atributo y una estrategia.

Recordemos que si algo inquietó a las vanguardias históricas fue el valor y peso de las instituciones. Sus artistas lo percibieron tan bien que arremetieron precisamente contra ellas, las instituciones culturales y estéticas, y contra el arte mismo como institución ${ }^{6}$. Su embate fue definitivo aunque no duró mucho. Y hoy, ya un siglo después, sabemos que tan fortificadas salieron las instituciones de quienes las combatieron, que es posible ver el reverso de aquellas guerras de hace casi un siglo. Si durante la modernidad las obras de arte y la literatura se convirtieron en el campo de batalla entre la estética y el mercado, hoy estos no

6 Me refiero aquí a la versión ya canónica de las vanguardias históricas establecida por Peter Bürger (Teoría de la vanguardia). 
necesariamente pelean dentro de la obra. Es posible incluso ver hasta qué punto la novedad en el arte puede venir más fuertemente de la institución -cualquiera que sea, incluso las que se oponen a las instituciones- que de las obras. Basta pensar en las formas de patrocinio del arte y la literatura (becas, estadías en residencias, premios, bienales, maestrías, alianzas con otras prácticas culturales como la moda y el diseño, los espacios televisivos) que imponen temáticas, extensiones, historias e, incluso, en las editoriales independientes, en los blogs, en la circulación de literatura en Internet. La gran novedad no es que esto suceda, sino que las instituciones culturales hayan pasado a ocupar un primer plano tan evidente que la obra, el artista o cualquier otra subjetividad ligada al arte y la cultura son telones de fondo de las operaciones institucionales. Las instituciones están todas, en diferentes medidas, ligadas al mercado, que ha pasado a ocupar también un primer plano. El protagonismo contemporáneo de las instituciones y el mercado no debe hacernos olvidar, sin embargo, que ambas instancias fueron decisivas en la historia del arte moderno; que siempre jugaron un rol importante desde el siglo XIX. Solo que hoy muchos artistas "de vanguardia" y sus obras tienen excelentes vínculos con las instituciones e incluso, en muchos casos, derivan su productividad de ellas. Esto es más obvio en el campo de las artes visuales pero la literatura ha sabido redefinir su lugar dentro de las instituciones. Podríamos decir que hoy gran parte de las obras y las instituciones trabajan juntas, generalmente en la misma dirección.

\section{Escritura e iluminación}

Me centraré en el caso de La novela luminosa de Mario Levrero, el escritor uruguayo que en el año 2000 ganó una beca de la Fundación Guggenheim para escribir un texto literario, que es el que leemos. La novela luminosa se escribió bajo los "efectos" -casi hipnóticos- de la beca y se publicó en 2005, un año después de su muerte. A pesar del uso de la palabra novela en el título, más de cuatrocientas páginas del texto no son la "novela" (cien páginas casi al final del volumen) sino el "Diario de la beca", como prólogo y epílogo a la obra, en el cual el narrador cuenta la historia de su relación con la propia escritura, con el dinero, el cuerpo y... con la Fundación Guggenheim. El "Diario" proporciona todo tipo de materiales, pero me interesa leerlo, ante todo, como una reflexión sobre la trama que se establece entre el arte, las instituciones culturales y la industria cultural. El texto es, en este sentido, una "confesión", pero más que de las vicisitudes de una conciencia o los trabajos de una subjetividad, lo es de las condiciones de trabajo de aquello que no es "verdaderamente un trabajo", o de cómo la literatura pasa a ser un "trabajo". El yo de ese texto se vincula principalmente con su neurosis 
para dejar en claro cómo trabaja el escritor en las condiciones contemporáneas. El "Diario" también cuestiona la práctica literaria, los géneros literarios, y el lugar de la autoridad, la escritura y las instituciones. Habla del "autor", pero lo hace desde el lugar en que las condiciones de trabajo se vuelven fundantes de la escritura. Podemos leer el "Diario" entonces como un experimento que consiste en reflexionar sobre la nueva institucionalización internacional de la cultura y sus efectos en las obras literarias. La novela de Levrero es un raro objeto de vanguardia que muestra nuevos vínculos entre escritura, política, mercado y autoridad. Pero no solo hace esto -que bien puede describir a lo que aspira mucha literatura contemporánea-; también hace que todos esos vínculos se muestren en su faz más problemática.

Como dije, en La novela luminosa de Levrero no se accede a la "novela" (para escribir la cual solicitó la beca) sino después del "Diario", en el que el narrador describe los protocolos que siguió para escribir su "gran obra" a lo largo de un año. Allí leemos de qué modo haber ganado la beca Guggenheim -y estar gastando sus fondos- es más un problema que una solución para el artista pobre, que siempre tuvo trabajos poco "artísticos" (dirigir talleres literarios, editar revistas de crucigramas, vender libros usados). Pero... ¿cómo puede el arte ser considerado un "trabajo" y hasta dónde puede un autor aprovecharse del dinero en su creación? Levrero explora el vínculo entre dinero y literatura, patrocinio y creatividad, poniendo al yo como instrumento de pesquisa, sometiéndolo a declararse simultáneamente un sujeto confesional -escribirá un diario de su escritura- pero también culpable ante la ley porque arte y dinero, en su conciencia, son parte de universos antagónicos.

Ese yo, sin embargo, descubre que no hay una línea recta entre literatura y dinero, de modo que el escritor comienza el proceso de trazarla comprando un sofá para poder sentarse confortablemente y tener tiempo para leer novelas policiales. Luego compra bibliotecas que llenará con las recientes adquisiciones de novelas policiales usadas, y más adelante un aire acondicionado y un nuevo teclado para su computadora; es decir, compra la infraestructura para escribir. A medida que avanza en estas mejoras siente que ha hecho malas inversiones, pues ha logrado mejorar su "vida" pero no su "literatura", pues su "novela" no avanza. Pero ¿qué sería invertir dinero en "literatura"? ¿Cómo darle satisfacción material a una práctica inmaterial? ¿Cómo transmutar el dinero en estética?

El dinero -en la versión capitalista que el narrador adopta- es tiempo. Así, comienza por organizar su tiempo: horarios para dormir; tiempo para navegar en la Web; para escribir, leer, comprar libros, comer, ver amigos y amigas, tomar antidepresivos. Diseña entonces un programa de computadora que lo ayude a 
manejar el tiempo y cumplir el propósito de escritura. A pesar del progresivamente más confortable ambiente de trabajo, el escritor es incapaz de escribir "literatura", su novela ${ }^{7}$. Pero... él escribe; escribe muchas páginas del "Diario" en el que deja constancia de su incapacidad de escribir. Y hay algo más.

En su relato, escribir es enfrentarse a la ley. El escritor no puede sacarse de la cabeza que hay un contrato: la Fundación Guggenheim dio dinero, el autor debe entregar su trabajo. La literatura es vista como un trabajo bajo el ojo panóptico de "Mr. Guggenheim" (el personaje que tiene, imaginariamente, control del manuscrito). Como un patrón, él cuida que el escritor escriba su novela, tal como prometió en el contrato, y que no gaste $s u$ (el de Mr. Guggenheim) dinero en cosas no-literarias. De este modo explora los límites entre literatura y vida. En lugar de una práctica creativa, la literatura -el arte- se vuelve una carga, una tarea que no se puede cumplir, y por ello aparece siempre el fantasma de estar ante un tribunal: el autor recibe fondos y es automáticamente culpable. El dinero es el vínculo de la culpa entre el mecenas y el autor, entre el sujeto y la literatura, y no solo en lo que tiene que ver con el manuscrito incompleto. El narrador compra cantidad de libros, pero solo libros usados (viejas y nuevas ediciones de novelas policiales), $\mathrm{y}$ atraviesa la ciudad, las pocas veces que sale, en busca de ediciones baratas de clásicos del género. En estas búsquedas, reproduce su relación paranoica con el dinero: siente que el librero de las librerías de usados lo está vigilando, temiendo que se robe libros, del mismo modo que siente que le roba a Mr. Guggenheim.

¿Cómo complacer simultáneamente al mecenas y a sí mismo? Esto parece imposible y hace crecer la culpa, pero también la escritura. La figura del mecenas domina el estado de la literatura y el arte en este contexto, y el dinero se vuelve parte de la escritura pues media los vínculos del narrador con la literatura (compra libros, bibliotecas, un sofá para leer y escribir). El contrato con la Fundación Guggenheim no requiere que el autor termine una gran novela, obviamente; el señor Guggenheim, ese interlocutor ficticio de buena parte del texto, no existe como un fiscal en la vida real. Sin embargo, representa el sistema de control donde la literatura y el arte se producen: la institución.

Dinero y patrocinio toman el centro de la escena; nada, nadie, puede desmantelar esta estructura neurótica que se centra en un contrato de trabajo que deviene relación sádica. Mr. Guggenheim, como Dios, vigila el trabajo del narrador que se siente retenido por el contrato; pero él no es un obrero, se ha convertido en un esclavo. El "Diario" registra muchos otros sentimientos y

7 En realidad -y para complicar las cosas- el escritor ha pedido la beca Guggenheim no para escribir sino para reescribir un viejo manuscrito, que será su novela luminosa. 
situaciones, no obstante, gran parte de la escena la ocupa el hecho de que el escritor vive la escritura como una culpa, pues se considera un traidor ante la figura omnipresente de Mr. Guggenheim. Como un esclavo, el narrador sueña con la oportunidad de la fuga, pero dentro de la escritura no hay fuga posible. Ella misma es una trampa que perpetúa su condena. Lo cierto es que el escritor no puede escribir su novela y por eso pasa los días espiando la vida de unas palomas del edificio contiguo, navegando en páginas pornográficas, creando un programa elemental para controlar los horarios de su propia vida, perdiendo el tiempo al tratar de resolver problemas domésticos (el calor, la comida, el insomnio). El escritor se revela ante la institución como el más ordinario de los seres humanos, aunque ha ganado la beca por su "excepcionalidad" como artista. En la vida cotidiana, la mirada de la institución y su propia experiencia se contraponen y la "profesión" se vuelve un tribunal perpetuo. El escritor aplica las condiciones de trabajo bajo el liberalismo al trabajo literario: se siente culpable por cobrar y "no hacer nada", y acompaña la culpa con el sufrimiento de su propio cuerpo (dolor de estómago, insomnio, alta presión) y la gradual desintegración de su propia personalidad (es incapaz de andar por la ciudad, pierde el tiempo durante un año, pierde a la mujer que ama).

El resultado es la parálisis dentro de una guerra latente del escritor con su mecenas. El imaginario Mr. Guggenheim acosa al escritor para controlarlo mejor, pero este lo traiciona porque no escribe su novela sino que escribe "sobre nada". El contrato se vuelve un fraude. $\mathrm{El}$ arte se vuelve un fraude porque entra en la máquina económica. Sin embargo, el resultado también será literatura, muchas páginas para Mr. Guggenheim quien, en el fondo, no habrá invertido tan mal su dinero. El escritor, el obrero-esclavo-traidor, realiza un sabotaje por su parte: escribe sobre nada, no en un sentido filosófico sino en uno material aunque, finalmente, después de un año de duro trabajo, termina el "Diario" y también la novela. Sin embargo, la novela "real" ya no puede despegarse del "Diario" de su producción, addenda recordatorio -como un documento legal, como un recibo de sueldo, como un contrato de trabajo- del intercambio de dinero que la precedió. En realidad, el resultado es un producto extraño, una obra en la que la escritura es parte de un proceso en el que el acto de escribir se vuelve visible porque hubo dinero de por medio. La literatura, en este caso, no es la construcción ni la deconstrucción, sino la exhibición de todo aquello que no es literatura pero que la hace posible. El libro entero es una exhibición de formas, procedimientos, procesos (como suele serlo el arte moderno), pero también de mecanismos. El mecanismo principal muestra cómo la literatura está atrapada en la red institucional aun cuando sea capaz de sobrevivir a las demandas institucionales. Este 
es el punto "luminoso" de la novela. No lo son la escritura, ni la tradición ni la novedad, sino la certeza de que el "arte" o la "estética" no existen fuera de una relación tensa con las instituciones y las formas convencionales de circulación. Por esta razón el libro toma la forma de un diario o una confesión (una escritura íntima). No porque el yo necesite ser redefinido sino porque es la literatura que escribe acerca de sí misma. El yo no es un sujeto biográfico, es un artista; la neurosis no es un síntoma sino una clase de relación institucional y de trabajo; la trama no es una historia personal sino un proceso que revela un problema. Por estas razones, una novela propiamente autobiográfica no puede ser biográfica. Mario Levrero es un sujeto legal; el sujeto que firmó el contrato con Mr. Guggenheim. El escritor obedece, confía en el modelo capitalista, quiere cumplir el contrato pero no puede. En este punto, crea algo nuevo: una narración que declara que no es posible permanecer obediente al mercado, las instituciones o el dinero, pero tampoco es posible ya situarse fuera de ellos.

Por eso, quizás, la forma irónica antecede todo el relato. Luego del índice una nota informa que: "Este libro fue escrito en su mayor parte gracias al generoso apoyo de la John Simon Guggenheim Foundation, a través de una beca otorgada en el año 2000". Y entre los agradecimientos figura la John Simon Guggenheim Foundation y "[...] quienes me han estimulado para que me presentara a concursar por la beca Guggenheim". Lo más definitivo quizás es otra nota firmada por "M. L.": "Las personas o instituciones que se sientan afectadas o lesionadas por opiniones expresadas en este libro deberán comprender que esas opiniones no son otra cosa que desvaríos de una mente senil”. M. L. logra expresar así su posición imposible, su posición de artista: sumisión y dominio, uso de la fundación como material literario pero también venganza personal a través de la locura y la vejez. Irónico, pero también repitiendo el gesto de toda la novela, M. L. no podrá, ni en los márgenes del texto, escapar de la institución aunque, al mismo tiempo, se sobrepone a ella, al afirmarse como autor. Por ello deberá inscribirla en la escritura, de múltiples modos.

Para terminar, quisiera recordar un episodio que tiene a la Fundación Guggenheim también como protagonista en un breve intento genealógico. En 1968 el artista argentino Federico Peralta Ramos ganó una beca Guggenheim. Por entonces, el arte latinoamericano no tenía mucha visibilidad en el campo internacional aunque trataba de conseguirla a través, precisamente, del patrocinio institucional ${ }^{8}$. Peralta Ramos decidió utilizar

8 En Vanguardia, internacionalismo y política. Arte argentino en los años sesenta, Andrea Giunta analiza pormenorizadamente el campo argentino del arte en relación con su impulso internacionalista. 
casi todo el dinero que le otorgó la beca en una cena para sus amigos en uno de los restaurantes más caros de Buenos Aires, que continuó en una discoteca. Con el dinero de la beca, además, se mandó a hacer tres trajes a medida, pagó deudas de una exposición, compró cuadros a sus amigos y puso el resto del dinero en una financiera. Si Leonardo da Vinci pintó La última cena, Federico Peralta Ramos la ofrece, "la hace", vuelve la obra una materialidad a través del dinero de la fundación. En una carta -otra escritura personal dirigida a "Mr. Mathias", el representante de la fundación-, escrita el 14 de junio de 1971, Peralta Ramos le describe pormenorizadamente el uso que le dio a los fondos de la beca (ver anexo). Cuando la Fundación Guggenheim recibe la carta, le pide que devuelva el dinero pero Peralta Ramos responde: "ustedes me dieron esa plata para que yo hiciera una obra de arte, y mi obra de arte fue la cena"; y agrega:

Una organización de un país que ha llegado a la Luna, que tenga la limitación de no comprender y valorizar la invención y la gran creación que ha sido la forma en que yo gasté el dinero de la beca, me sumerge en un mundo de desconcierto y asombro. Devolver los tres mil dólares que Uds. me piden sería no creer en mi actitud, por lo tanto he decidido no devolverlos. Esperando que estas líneas sean interpretadas con temperamento artístico, saludo a Uds. muy atentamente, Federico Manuel Peralta Ramos. ${ }^{9}$

Entre ambos episodios median años que no solo son muchos sino decisivos para los cambios en las artes y la cultura, y la relación con el dinero y el mercado. A esos cambios sobrevivieron el arte y las instituciones culturales. Y también sobrevivió el yo, aunque radicalmente transformado. La primera persona que se dirige a la Fundación Guggenheim en la voz de Peralta Ramos habla desde la "superioridad del arte" y coloca a la institución en un lugar subordinado, que debe acatar sus "caprichos" ${ }^{10}$. La novela de Levrero subordina la voz del artista al control de la institución que impone sus reglas y el artista dispone solo de pequeñas venganzas. En los dos casos, la "obra" resulta de la tensión entre el artista y la institución,

9 Las cartas están reproducidas en el sitio web <http://www.macromuseo.org.ar/coleccion/ artista/p/peralta_ramos_federico.html>.

10 Pedro Roth, amigo de Peralta Ramos, cuenta que esa carta (que aparentemente fue enmarcada y colgada en las oficinas de la institución) hizo que la Fundación Guggenheim cambiara su política sobre la rendición de cuentas de la beca. Después de Peralta Ramos nunca más pidió justificación de los gastos. Ver Gainza. 
una tensión en la que se juega el poder de cada uno y el poder toma la forma de una primera persona. Ese es, en parte, el "poder del arte": crear lugares de enunciación cuya correspondencia con la realidad es menos relevante que su potencia de interpelación, aquellos lugares que rompen la continuidad de las series.

\section{Anexo}

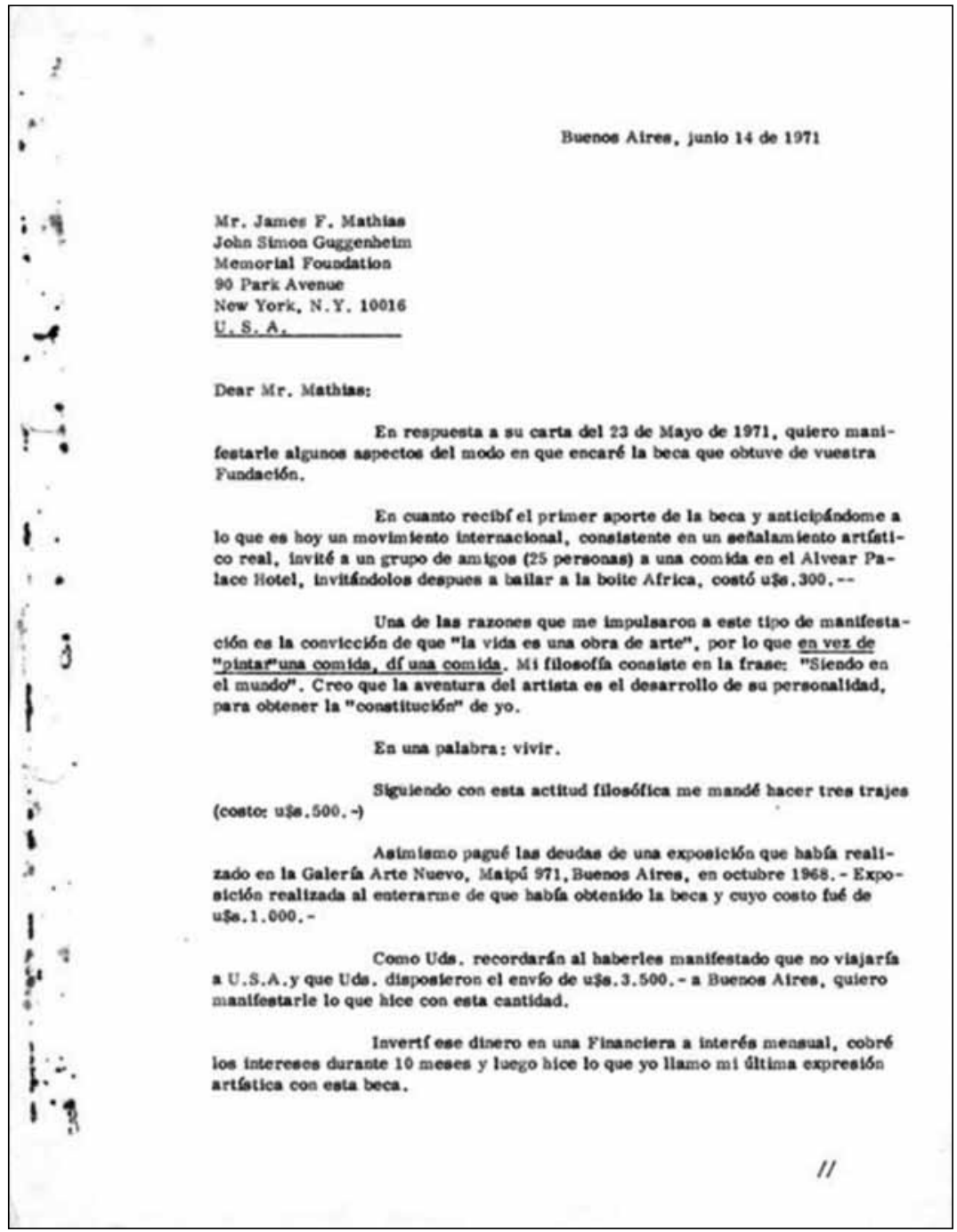




\section{Obras citadas}

Gainza, María. "Federico el Grande". Radar, suplemento de

Página/12. 7 sept. 2003. Web. <http://www.pagina12.com.ar/

diario/suplementos/radar/9-926-2003-09-07.html>.

Giordano, Alberto. El giro autobiográfico de la literatura

argentina actual. Buenos Aires: Mansalva, 2008.

Giunta, Andrea. Vanguardia, internacionalismo y política. Arte argentino en los años sesenta. Buenos Aires: Paidós, 2001.

Laddaga, Reinaldo. Estética de la emergencia. La formación de otra cultura de las artes. Buenos Aires: Adriana Hidalgo, 2006.

Levrero, Mario. La novela luminosa. Montevideo: Alfaguara, 2005.

Lorey, Isabell. "Gubernamentalidad y precarización de sí. Sobre la normalización de los productores y productoras culturales". Producción cultural y prácticas instituyentes. Líneas de ruptura en la crítica institucional. Ed. Transform. Madrid: Traficantes de Sueños, 2008. 57-78.

Ludmer, Josefina. Aquí América Latina. Una especulación. Buenos Aires: Eterna Cadencia, 2010.

Marrone, Irene. Imágenes del mundo histórico. Identidades y representaciones en el noticiero y el documental en el cine mudo argentino. Buenos Aires: Biblos; Archivo General de la Nación, 2003.

Peralta Ramos, Federico. "Cartas a la Fundación Guggenheim”. 1971, 14 de junio. Web. <http://www.macromuseo.org.ar/coleccion/artista/p/peralta_ramos_federico.html>

Rancière, Jacques. Le partage du sensible: estétique et polique. París: La Fabrique, 2000. 